\title{
Huntington disease-like 1
}

INSERM

\section{Source}

INSERM. (1999). Orphanet: an online rare disease and orphan drug data base.

Huntington disease-like 1. ORPHA:157941

A rare, genetic, human prion disease characterized by adult-onset neurodeg enertaive manifestations associated with a movement disorder and psychiatric/behavioral disturbances. Patients typically present personality changes, aggressiveness, manias, anxiety and/or depression in conjunction with rapidly progressive cognitive decline (presenting with dysarthria, apraxia, aphasia, and eventually leading to dementia) as well as ataxia (manifesting with gait disturbances, unsteadiness, coordination problems), Parkinsonism, myoclonus, and/or chorea. Additional features may include generalized spasticity, seizures, urine incontinence and pyramidal abnormalities. 